EDITORIAL

Rev Obstet Ginecol Venez. 2021; 81 (1): 1-4

https://doi.org/10.51288/00810103

\title{
Revista de Obstetricia y Ginecología de Venezuela, ;Ochenta años de publicación ininterrumpida!
}

\author{
Dra. Mireya González Blanco
}

Directora/Editora

Con enorme orgullo y satisfacción publicamos el primer número del volumen 81 de la Revista de Obstetricia y Ginecología de Venezuela. Esto quiere decir, que estamos arribando a los 80 años de existencia. Han sido años de mucho esfuerzo, pero afortunadamente, en este tiempo hemos podido cosechar numerosos éxitos. Iniciar una publicación periódica no es fácil, requiere preparación, dedicación, trabajo, sortear dificultades, trabajo en equipo, apoyo institucional, estímulo para los investigadores, todo ello acompañado de un enorme entusiasmo y gran perseverancia. Pues bien, si iniciar una publicación es un proceso complejo, lo es, aún más, mantenerse en el tiempo.

En la presentación de la revista hecha en el editorial publicado en el número 1 del año 1, en 1941 (1), se lee:

"El incremento que la Obstetricia ha tomado entre nosotros, debido al aumento de profesionales que se ha dedicado a esta rama de la medicina especialmente, a lo cual se agrega la fundación de la Maternidad Municipal "Concepción Palacios", ha sido el origen de la creación de la Sociedad de Obstetricia y Ginecología de Venezuela. Y como consecuencia directa de las actividades de esta Sociedad es la fundación de la presente Revista, que le servirá de órgano. Entre nosotros la experiencia ha demostrado que muchas de las revistas científicas no tenían razón de ser. La efímera existencia que tuvieron fue la prueba de que su aparición no obedeció a una necesidad y creemos no equivocarnos al presagiar que la nuestra no seguirá la misma suerte".

¡Cuánta razón tuvieron nuestros primeros directores! Han sido 80 años cumpliendo puntual e ininterrumpidamente con la sagrada labor de difundir el conocimiento médico en Obstetricia y Ginecología. Profesionales médicos de la especialidad y áreas afines, a nivel nacional e internacional, suministran el material científico que da vida a la publicación, un maravilloso grupo de especialistas, docentes e investigadores, actúan como árbitros para la selección de los mejores documentos y, posteriormente, el comité editorial, conformado por especialistas expertos, con quienes tengo el honor de trabajar y de quienes he aprendido a lo largo de mi formación como especialista, corrige el estilo para hacer que los artículos lleguen en la mejor forma posible a nuestros lectores. Con esto combinamos las cuatro "S" de una publicación. Mientras que el tema (subject) y la estrategia (strategy) forman el trasfondo, que depende de los investigadores y es considerado fundamental para la aprobación por parte de los árbitros, la estructura (structure) y el estilo (style) representan la forma y es responsabilidad del Comité Editorial que cumplan con los estándares internacionales. Adicionalmente, para nosotros, la publicación de un artículo científico requiere que se cumplan cuatro criterios básicos e ineludibles: credibilidad, originalidad, claridad y relevancia para sus lectores. 
Muchos han sidolos retos afrontados y, en su mayoría, superados. Es costumbre que periódicamente se expresen los logros y las dificultades por las que hemos pasado como institución. Agüero (2), en 2003, publicó su Historia de la Sociedad de Obstetricia y Ginecología de Venezuela y le dedicó todo un capítulo a la revista. Allí, entre otras cosas, precisamente, reseña esos logros y avatares a 10 largo de los primeros 60 años de publicación. El mantenerse en el tiempo con publicaciones de gran calidad, es el principal logro. Entre los avatares que se han tenido que sortear, menciona problemas económicos, de escasez de material científico y publicitario, dificultades con los impresores e insuficiente colaboración médica.

Han transcurrido 80 años desde su nacimiento y, poco a poco, hemos ido avanzando, superando obstáculos.

Antes de mi llegada a la dirección-edición, esta había estado en manos de relevantes personalidades de la especialidad: en orden temporal, los Drs. Leopoldo Aguerrevere (1941-1944), Odoardo LeónPonte (1945-1947), Oscar Agüero (1948-1990), Itic Zighelboim (1991-1994), Jacqueline Saulny de Jorges (desde julio 1994-2006) y Ofelia Uzcátegui (2006-2016). Además, el Dr. Agüero fue designado Director Emérito el 28 enero de 1992. Estos ilustres directores-editores trabajaron de la mano de un destacado grupo de redactores. Todos ellos han cumplido una encomiable labor, ubicando a la revista entre las mejores del país, e incluso de Latinoamérica, como lo demuestran los premios obtenidos y los reconocimientos nacionales e internacionales (2). En sus manos, fue publicada puntualmente cada trimestre, en papel hasta el número 3 del volumen 74, año 2014 inclusive, y se encuentra publicada en formato digital en la página web de la Sociedad de Obstetricia y Ginecología de Venezuela desde el número 1, volumen 58, año 1998. Lamentablemente, a partir del número 4 del volumen 74, problemas para la obtención del papel, hicieron que se convirtiera en una publicación exclusivamente digital.
A lo largo del tiempo, el estilo ha variado, siempre adaptándose a los requisitos o recomendaciones internacionales. El formato actual, a dos columnas, es de fácil lectura y la publicación digital admite la incorporación de mejores imágenes, incluso a color, sin costo adicional. Para el texto, solicitamos a los interesados en formar parte de nuestros autores que se guíen por las recomendaciones del Comité Internacional de Editores de Revistas Médicas (3), las cuales se actualizan periódicamente en respuesta a las necesidades de la ciencia, y nosotros nos actualizamos y modernizamos con ellas y, mediante las Normas de Publicación (4), los guiamos en el proceso.

Ahora bien, la adecuada dirección es importante, el trabajo del Comité de redacción es fundamental y la modernización de la publicación es indispensable. Pero la base más importante para el éxito, está conformada por los investigadores que envían sus trabajos para ser publicados. Hoy en día, la producción científica se ha incrementado, hemos recibido una gran cantidad de artículos originales, producto de investigación nacional que se origina en universidades, principalmente las versiones para publicar de los trabajos especiales de grado, trabajos de incorporación como miembro titular de la Sociedad y también numerosos documentos que se originan en otras instituciones del país, así como investigaciones internacionales, provenientes de Latinoamérica y Europa. También recibimos revisiones de temas relevantes, realizadas por especialistas obstetras y ginecólogos del país con amplia experiencia en el campo, y reportes de casos clínicos interesantes, novedosos o poco frecuentes, que permiten a todo el que la lee documentarse y mantenerse actualizado.

Uno de los problemas que enfrentamos actualmente tiene que ver con la visibilidad de nuestras publicaciones. A través de los años, la producción científica de los países que pertenecen a Centro América y el Caribe no se divulgaba de manera adecuada entre investigadores de forma tal que se 
pudiera compartir o intercambiar el conocimiento científico, lo que hacía difícil que el contenido investigado estuviera a disposición de otros investigadores, así como a la comunidad educativa y el público en general. En la actualidad se han desarrollado en la región numerosas iniciativas para mejorar la divulgación y la calidad de las publicaciones a través de plataformas que permiten visibilizar la producción científica publicada en acceso abierto, haciendo más visible la producción científica y académica. La difusión de los artículos es una de las tareas fundamentales del equipo editorial de una revista científica, junto a la selección de los mejores trabajos. Hoy día, es una apuesta importante en una sociedad cada vez más abierta y conectada. Es indispensable cumplir de forma rigurosa con los procesos de selección y revisión de los trabajos que se publican y que el equipo editorial cumpla con profesionalidad, transparencia y calidad con su trabajo, pero también es necesario garantizar la difusión, preferiblemente en acceso abierto, de los contenidos, por lo que estamos comprometidos con los autores en trabajar para que sus artículos puedan ser leídos por el mayor número de expertos en la temática.

La Revista de Obstetricia y Ginecología de Venezuela, órgano oficial de divulgación científica de la Sociedad de Obstetricia y Ginecología de Venezuela, es una publicación periódica formal, arbitrada, de aparición trimestral cuyos artículos están disponibles en acceso abierto a través de la página http:// www.sogvzla.org.ve/sogvzla20186/ sacirevista.php. Está indexada en SciELO Venezuela, y actualizada en esa base de datos hasta 2017. A partir de 2018, la plataforma de SciELO Venezuela ha venido presentando numerosos inconvenientes, razón por la cual todas las publicaciones venezolanas indexadas en esa base de datos no tienen visibilidad en línea, perdiéndose así esta opción para visibilizar los resultados de investigación de los autores venezolanos y limitando la oportunidad de internacionalizar su experiencia científica al intercambiar ideas con investigadores regionales. Desde entonces se han realizado numerosas diligencias, en conjunto con la Asociación de Editores de Revistas Biomédicas Venezolanas (ASEREME), con la finalidad de solventar los inconvenientes, pero, lamentablemente, en julio de 2019, la Fundación del Sistema Nacional de Documentación e Información Biomédica (FUNDASINADIB), encargada de la gerencia de SciELO Venezuela, recibió una comunicación de la gerencia de SciELO Brasil, en la que se le informa que tras sucesivas evaluaciones de la colección SciELO Venezuela, se revocaba el estatus de colección certificada a partir del primero de agosto 2019 y, actualmente, figura como una colección con el estatus "en desarrollo".

A partir de ese momento, la dirección se abocó a incluirla en otras bases de datos, proceso largo y exigente, pero que, con toda seguridad resultará exitoso, dada la elevada calidad de las publicaciones que se presentan. En este sentido, iniciamos trámites para formar parte del catálogo digital Saber UCV y nos complace informar que, desde enero de 2020, la Revista de Obstetricia y Ginecología de Venezuela forma parte de la comunidad de Open Journal System en Saber UCV, habiéndose incorporado al repositorio todos los artículos, a partir del volumen 78 (2018). En los actuales momentos, nos encontramos haciendo los trámites necesarios para actualizar la incorporación a otros indizadores regionales, como la base de datos de Literatura Latinoamericana de Información en Ciencias de la Salud (LILACS), la base de datos de Literatura Venezolana en Ciencias de la Salud (LIVECS) y el Sistema Regional de Información en Línea para Revistas Científicas de América Latina, el Caribe, España y Portugal (Latindex). Los mantendremos informados.

Siguiendo la línea de actualización y modernización, nos empeñamos en adquirir el identificador de objeto digital (DOI) tanto para la revista como para los artículos que se publiquen. De esta manera estamos conectando nuestro contenido con la red global de investigación académica en línea, porque la membresía de Crossref (organismo que 
gerencia el DOI), nos permite conectar nuestro contenido con una red global de 17322 miembros en más de 139 países. Nuestro DOI es https:// doi.org/10.51288/042020 y ya el número 4 del volumen 80 está registrado. Nos encontramos en estos momentos registrando los artículos de ese número en forma individual.

Entre las propuestas que se están desarrollando para la modernización está el registro de los investigadores en el Open Researcher and Contributor Identification (ORCID). Es un código alfanumérico, no comercial, que identifica de manera única a científicos y otros autores académicos a nivel mundial. El Comité Editorial insta a los autores a registrarse, es un procedimiento sencillo y gratuito que evita errores de autoría por confusión de nombres o por cambio de apellidos en el tiempo.

Tal como decía el Dr. Agüero, en 1990, “A pesar de las vicisitudes, sinceramente creemos que la revista ha cumplido, y esperamos siga cumpliendo, el presagio expresado en la editorial del primer número. Ha servido y debe seguir sirviendo de medio de expresión y comunicación de los tocoginecólogos venezolanos, entre sí y con el exterior del país" (2). Sigo pensando, como en 2016, que tenemos al frente un trabajo duro, mantener el nivel, e incluso tratar de subirlo. Este equipo asume el reto con gran responsabilidad y voluntad de trabajo, siempre receptivos de las enseñanzas obtenidas de quienes nos precedieron y de las críticas, esperamos constructivas, de nuestros lectores. Contamos con el apoyo de la Junta Directiva de nuestra sociedad, quienes han mostrado interés y han hecho todo su esfuerzo para mantenerla. A ellos y, en general, a todos los ginecobstetras del país, les decimos que seguiremos empeñados en mantener la revista por lo menos por otros 80 años más. ¡Enhorabuena!

\section{REFERENCIAS}

1. Editorial. Rev Obstet Ginecol Venez. 1941; 1(1):1-2.

2. Agüero O. Historia de la Sociedad de Obstetricia y Ginecología de Venezuela. Caracas: Editorial Ateproca; 2003.

3. ICMJE. International Committee of Medical Journals Editors [Internet]. Vancouver: Recommendations for the Conduct, Reporting, Editing, and Publication of Scholarly Work in Medical Journals; 2019 [actualizado diciembre de 2019; consultado 18 de octubre de 2020]. Disponible en: http://www.icmje. org/recommendations/

4. Sociedad de Obstetricia y Ginecología de Venezuela [Internet]. Caracas: Normas de publicación. Instrucciones para publicar en la Rev Obstet Ginecol Venez; 2020 [consultado 18 de enero de 2021]. Disponible en: http://www.sogvzla.org.ve/ sogvzla20186/pdfs/15normaspublicacion.pdf 